\title{
A kinetic study of the reaction of atomic hydrogen with iodobenzene
}

\author{
Yide Gao $^{\mathrm{a}}$, Kimberly Fessel ${ }^{\mathrm{b}}$, Chris McLeod ${ }^{\mathrm{a}}$, Paul Marshall ${ }^{\mathrm{a}, *}$ \\ ${ }^{a}$ University of North Texas, Department of Chemistry, P.O. Box 305070, Denton, TX 76203-5070, USA \\ ${ }^{\mathrm{b}}$ University of Evansville, Department of Chemistry, 1800 Lincoln Avenue, Evansville, IN 47722, USA
}

Received 19 July 2007; in final form 21 November 2007

\begin{abstract}
The rate constant for the reaction of $\mathrm{H}$ atoms with phenyl iodide has been measured using the laser flash-photolysis technique with detection of $\mathrm{H}$ by resonance fluorescence. The data over $295-907 \mathrm{~K}$ are summarized by the expression $k=1.45 \times 10^{-18} T^{2.50} \exp (74 / T)$ $\mathrm{cm}^{3}$ molecule ${ }^{-1} \mathrm{~s}^{-1}$ with a $95 \%$ confidence limit for $k$ of $\pm 8 \%$. Ab initio analysis suggests the dominant products are phenyl and hydrogen iodide.

(C) 2007 Elsevier B.V. All rights reserved.
\end{abstract}

\section{Introduction}

Reactions of hydrogen atoms with alkyl iodides have been the subject of several kinetic studies [1-7], motivated in part by the potential contributions of iodine to combustion chemistry [8]. Interesting kinetics have been observed in some cases, such as Cl-atom addition [9] and O-atom addition followed by elimination of HOI [10]. Rather less attention has been paid to aryl iodides, which are of fundamental interest because they exhibit a range of mechanisms in radical reactions. For example, the reaction $\mathrm{CH}_{3}+$ $\mathrm{C}_{6} \mathrm{H}_{5} \mathrm{I}$ appears to proceed via I-atom abstraction [11], as does $\mathrm{I}+\mathrm{C}_{6} \mathrm{H}_{5} \mathrm{I}$ [12]. The $\mathrm{Cl}+\mathrm{C}_{6} \mathrm{H}_{5} \mathrm{I}$ reaction was proposed to take place by an addition/I-atom elimination path [13], while $\mathrm{OH}+\mathrm{C}_{6} \mathrm{H}_{5} \mathrm{I}$ appears to take place by addition below room temperature, and by $\mathrm{H}$-atom abstraction at higher temperatures [14].

We use $\mathrm{C}_{6} \mathrm{H}_{5} \mathrm{I}$ as a photolytic source of $\mathrm{C}_{6} \mathrm{H}_{5}$ to study the chemistry of phenyl radicals, and in the course of this work have characterized the process

$\mathrm{H}+\mathrm{C}_{6} \mathrm{H}_{5} \mathrm{I} \rightarrow$ products

\footnotetext{
${ }^{*}$ Corresponding author. Fax: +1 9405654318.

E-mail address: marshall@unt.edu (P. Marshall).
}

In this Letter, we report the first kinetic information concerning reaction (1), obtained with the time-resolved resonance fluorescence technique over $295-907 \mathrm{~K}$.

\section{Experimental section}

The experiments were performed with the laser flashphotolysis technique using resonance fluorescence detection of $\mathrm{H}$. Details of the apparatus and its operation have been previously described [15-18]. Therefore, only a brief description of the experiment will be presented here. The atomic hydrogen was generated by excimer laser (Lambda Physik Compex 102) photolysis of the precursor $\mathrm{NH}_{3}$ at $193 \mathrm{~nm}$. The relative concentration of $\mathrm{H}$ atoms was monitored by time-resolved resonance fluorescence at the Lyman- $\alpha$ wavelength, $121.6 \mathrm{~nm}$. This probe radiation was produced by a microwave discharge lamp with a flow of $0.2 \% \mathrm{H}_{2}$ in 0.14 mbar of Ar. Fluorescence was detected using a solar-blind photomultiplier tube with pulse counting. Typically $200-2500$ fluorescence vs time profiles were summed at each set of conditions, with a repetition rate of $2 \mathrm{~Hz}$. The temperature $T$ in the reaction zone was measured as in previous work [19]. The experiments were conducted in a large excess of Ar bath gas to thermalize the system and to slow diffusion of $\mathrm{H}$ to the reactor walls. The $\mathrm{C}_{6} \mathrm{H}_{5} \mathrm{I}$ and $\mathrm{NH}_{3}$ concentrations were derived from 
the mole fractions of these species in manometrically prepared mixtures with Ar, the total pressure $P, T$, and the gas flows which were measured with calibrated mass-flow controllers. The average residence time of gas mixtures in the heated reactor before photolysis, $\tau_{\text {res, }}$ was varied to check for possible pyrolysis of the iodobenzene and for mixing effects. Low photolysis energies $F$ were employed, to minimize secondary chemistry involving photolysis or reaction products.

All experiments were carried out under pseudo-firstorder conditions with $\mathrm{C}_{6} \mathrm{H}_{5} \mathrm{I}$ in large excess over $\mathrm{H}$, and with fixed precursor concentration $\left[\mathrm{NH}_{3}\right]$. Thus, the $\mathrm{H}$ atom temporal profile is dominated by reaction (1), with other loss processes described by an effective first-order decay constant $k_{2}$

$\mathrm{H} \rightarrow$ loss

A typical time-resolved fluorescence signal decay of atomic $\mathrm{H}$ is shown as the inset in Fig. 1. After the photolysis pulse, the variation of $[\mathrm{H}]$ is described by

$$
\mathrm{d}[\mathrm{H}] / \mathrm{d} t=-\left(k_{1}\left[\mathrm{C}_{6} \mathrm{H}_{5} \mathrm{I}\right]+k_{2}\right)[\mathrm{H}]=-k_{\mathrm{ps} 1}[\mathrm{H}]
$$

which implies an exponential decay of $[\mathrm{H}]$ with time $t$

$$
[\mathrm{H}]=[\mathrm{H}]_{0} \exp \left(-k_{\mathrm{ps} 1} t\right)
$$

$k_{2}$ increased as the pressure was lowered, and increased as the temperature was raised, which is consistent with the idea that $k_{2}$ reflects mainly diffusion of $\mathrm{H}$ atoms out of the observation zone. This loss was seen to be sensibly exponential. The $\mathrm{H}+\mathrm{NH}_{3}$ reaction also makes a minor contribution to $k_{2}$ at the highest temperatures [20]. $k_{\mathrm{ps} 1}$ and its statistical error were obtained by non-linear fitting of the observed fluorescence, with an allowance for a constant background arising from scattered probe radiation and/or fluorescent species, to the form of Eq. (4) $[21,22]$.

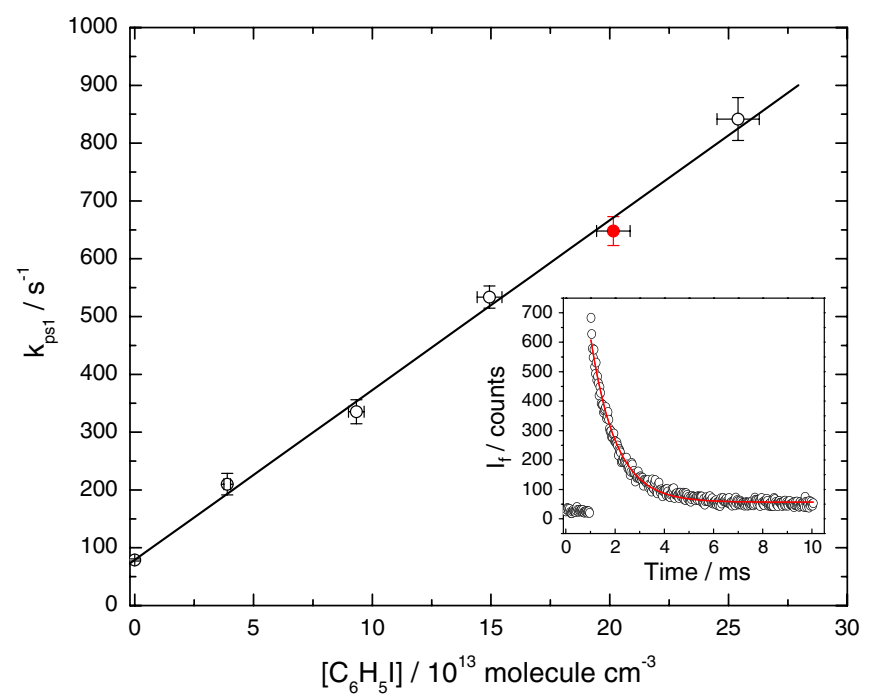

Fig. 1. Plot of $k_{\mathrm{ps} 1}$ vs $\left[\mathrm{C}_{6} \mathrm{H}_{5} \mathrm{I}\right]$ at $295 \mathrm{~K}$ and $68 \mathrm{mbar}$ Ar pressure. The inset shows the exponential decay of $[\mathrm{H}]$ with $\left[\mathrm{C}_{6} \mathrm{H}_{5} \mathrm{I}\right]=2.0 \times 10^{14}$ molecule $\mathrm{cm}^{-3}$. Error bars represent $\pm 1 \sigma$ statistical uncertainty.
We note that a long-lived reaction product fluoresced sufficiently to raise the background after photolysis by typically $3 \%$ of the $\mathrm{H}$-atom signal, but because this emission decayed very slowly, changes in $[\mathrm{H}]$ were isolated by the short time scale. The second-order $\mathrm{H}+\mathrm{C}_{6} \mathrm{H}_{5} \mathrm{I}$ rate constant $k_{1}$ was found from the slope of linear plots of $k_{\mathrm{ps} 1}$ vs typically six values of $\left[\mathrm{C}_{6} \mathrm{H}_{5} \mathrm{I}\right]$, from 0 to $\left[\mathrm{C}_{6} \mathrm{H}_{5} \mathrm{I}\right]$ max (see Fig. 1). $k_{2}$ is the intercept. The absolute concentration $[\mathrm{H}]$ was not measured (and is not required for the determination of $k_{\mathrm{ps} 1}$ ), but we can estimate the initial concentration $[\mathrm{H}]_{0}$ from $\left[\mathrm{NH}_{3}\right]$ and its absorption cross-section at $193 \mathrm{~nm}$ [23]. Because $\mathrm{C}_{6} \mathrm{H}_{5} \mathrm{I}$ might absorb on the reactor surface, the $\mathrm{C}_{6} \mathrm{H}_{5} \mathrm{I}$ mixtures were flowed through the apparatus for at least $3 \mathrm{~h}$ before experiments were begun, to passivate the surfaces.

Reagent grade $\mathrm{C}_{6} \mathrm{H}_{5} \mathrm{I}(98 \%$, Aldrich) was distilled from room temperature to $77 \mathrm{~K}$ before use, and $\mathrm{NH}_{3}$ (MG Industries, $99.99 \%$ ) was purified by freeze-pump-thaw cycles at $77 \mathrm{~K}$. Ar (Air Products, 99.9997\%) was used directly from the cylinder.

\section{Results}

The experimental conditions and 39 results for the second-order rate constant for the reaction of $\mathrm{C}_{6} \mathrm{H}_{5} \mathrm{I}+\mathrm{H}$ are summarized in Table 1 along with the statistical error in plots of $k_{\mathrm{ps} 1}$ vs $\left[\mathrm{C}_{6} \mathrm{H}_{5} \mathrm{I}\right]$. The results demonstrate the invariance of $k_{1}$ with both the total pressure and the $\left[\mathrm{C}_{6} \mathrm{H}_{5} \mathrm{I}\right] /[\mathrm{H}]_{0}$ ratio. The independence of the $k_{1}$ results from $F$ shows that secondary chemistry involving photolysis or reaction products was negligible, and confirms that pseudo-first-order conditions were attained.

Kumaran et al. have studied the unimolecular dissociation of $\mathrm{C}_{6} \mathrm{H}_{5} \mathrm{I}$ to $\mathrm{C}_{6} \mathrm{H}_{5}+\mathrm{I}$ over $1082-1416 \mathrm{~K}$ [24]. Their theoretical 'model (b)' for the high-pressure limit, extrapolated down to our highest temperature, implies that, at the longest residence time in the reactor, ca. $40 \%$ of the $\mathrm{C}_{6} \mathrm{H}_{5} \mathrm{I}$ might be expected to dissociate. The invariance of our $k_{1}$ data with $\tau_{\text {res }}$ suggests that little dissociation in fact occurred, in part because the initially cold gas flow does not spend all of $\tau_{\text {res }}$ at the temperature of the reaction zone. Any $\mathrm{C}_{6} \mathrm{H}_{5}$ produced will be rapidly consumed by reaction with $\mathrm{C}_{6} \mathrm{H}_{5} \mathrm{I}$, with a rate constant of about $2 \times$ $10^{-11} \mathrm{~cm}^{3}$ molecule ${ }^{-1} \mathrm{~s}^{-1}$ [25]. At $900 \mathrm{~K}$ and with a typical $\left[\mathrm{C}_{6} \mathrm{H}_{5} \mathrm{I}\right]=4 \times 10^{13}$ molecule $\mathrm{cm}^{-3}$, a steady state concentration of around $1.5 \times 10^{10}$ molecule $\mathrm{cm}^{-3}$ would be attained, which is too small to perturb the $[\mathrm{H}]$ profiles.

In Fig. 2 the data are presented in Arrhenius form. Curvature can clearly be seen. An empirical fit to the data, weighted by the uncertainties in $k_{1}$ and $T$, gives

$$
\begin{aligned}
k_{1}= & (1.45 \pm 2.01) \times 10^{-18} T^{2.50 \pm 0.19} \\
& \times \exp ((74 \pm 89) / T) \mathrm{cm}^{3} \text { molecule } \mathrm{e}^{-1} \mathrm{~s}^{-1}
\end{aligned}
$$

$95 \%$ statistical errors for $k_{1}$ from this expression are up to $6 \%$. Combining this in quadrature with an estimated propagated 5\% error arising from potential uncertainties in the 
Table 1

Summary of measurements of the rate constant $k_{1}$ for $\mathrm{H}+\mathrm{C}_{6} \mathrm{H}_{5} \mathrm{I}$

\begin{tabular}{|c|c|c|c|c|c|c|c|c|}
\hline $\begin{array}{l}T \\
(\mathrm{~K})\end{array}$ & $\begin{array}{l}\tau_{\text {res }} \\
(\mathrm{s})\end{array}$ & $\begin{array}{l}F \\
(\mathrm{~mJ})\end{array}$ & $\begin{array}{l}P \\
\text { (mbar) }\end{array}$ & $\begin{array}{l}{\left[\mathrm{NH}_{3}\right]} \\
\left(10^{14} \text { molecule } \mathrm{cm}^{-3}\right)\end{array}$ & $\begin{array}{l}{\left[\mathrm{C}_{6} \mathrm{H}_{5} \mathrm{I}\right]_{\max }} \\
\left(10^{13} \text { molecule } \mathrm{cm}^{-3}\right)\end{array}$ & $\begin{array}{l}{[\mathrm{H}]_{0}\left(10^{11}\right.} \\
\left.\text { molecule } \mathrm{cm}^{-3}\right)\end{array}$ & $\begin{array}{l}k_{2} \\
\left(\mathrm{~s}^{-1}\right)\end{array}$ & $\begin{array}{l}k_{1} \pm \sigma_{\mathrm{k} 1}\left(10^{-12} \mathrm{~cm}^{3}\right. \\
\left.\text { molecule }{ }^{-1} \mathrm{~s}^{-1}\right)\end{array}$ \\
\hline 295 & 3.0 & 0.06 & 69 & 7.72 & 31.0 & 5.3 & 68 & $2.72 \pm 0.15$ \\
\hline 295 & 3.0 & 0.04 & 69 & 7.72 & 31.0 & 3.5 & 77 & $2.60 \pm 0.15$ \\
\hline 295 & 3.0 & 0.02 & 69 & 7.72 & 31.0 & 1.6 & 77 & $2.52 \pm 0.10$ \\
\hline 295 & 5.2 & 0.08 & 68 & 8.77 & 25.4 & 7.5 & 50 & $3.65 \pm 0.14$ \\
\hline 295 & 5.2 & 0.05 & 68 & 8.77 & 25.4 & 4.8 & 45 & $3.31 \pm 0.09$ \\
\hline 295 & 5.2 & 0.03 & 68 & 8.77 & 25.4 & 2.6 & 49 & $2.95 \pm 0.11$ \\
\hline 295 & 2.2 & 0.09 & 29 & 6.55 & 25.3 & 6.3 & 149 & $2.38 \pm 0.16$ \\
\hline 295 & 2.2 & 0.06 & 29 & 6.55 & 25.3 & 4.3 & 136 & $2.49 \pm 0.15$ \\
\hline 295 & 2.2 & 0.03 & 29 & 6.55 & 25.3 & 2.0 & 140 & $2.30 \pm 0.09$ \\
\hline 295 & 3.2 & 0.10 & 72 & 1.49 & 23.4 & 1.6 & 51 & $2.41 \pm 0.21$ \\
\hline 295 & 3.2 & 0.06 & 72 & 1.49 & 23.4 & 1.0 & 54 & $2.33 \pm 0.17$ \\
\hline 296 & 3.1 & 0.06 & 69 & 1.66 & 35.0 & 1.1 & 71 & $2.70 \pm 0.23$ \\
\hline 297 & 4.6 & 0.01 & 83 & 2.42 & 51.2 & 0.3 & 70 & $3.11 \pm 0.19$ \\
\hline 407 & 3.9 & 0.14 & 71 & 6.87 & 17.2 & 10.6 & 107 & $6.81 \pm 0.23$ \\
\hline 407 & 3.9 & 0.06 & 71 & 6.87 & 17.2 & 4.6 & 119 & $6.25 \pm 0.22$ \\
\hline 407 & 3.9 & 0.04 & 71 & 6.87 & 17.2 & 3.0 & 113 & $6.16 \pm 0.18$ \\
\hline 407 & 3.9 & 0.02 & 71 & 6.87 & 17.2 & 1.7 & 94 & $6.62 \pm 0.21$ \\
\hline 515 & 2.9 & 0.11 & 68 & 6.59 & 17.9 & 8.0 & 234 & $9.63 \pm 0.72$ \\
\hline 515 & 2.9 & 0.07 & 68 & 6.59 & 17.9 & 5.0 & 218 & $10.4 \pm 0.84$ \\
\hline 515 & 2.9 & 0.03 & 68 & 6.59 & 17.9 & 2.5 & 252 & $9.82 \pm 0.63$ \\
\hline 515 & 5.8 & 0.08 & 135 & 6.25 & 12.3 & 5.3 & 125 & $12.3 \pm 0.91$ \\
\hline 515 & 5.8 & 0.05 & 135 & 6.25 & 12.3 & 3.7 & 160 & $12.3 \pm 0.95$ \\
\hline 517 & 1.4 & 0.14 & 68 & 4.71 & 16.3 & 7.3 & 358 & $8.89 \pm 0.74$ \\
\hline 517 & 1.4 & 0.08 & 68 & 4.71 & 16.3 & 4.2 & 359 & $9.01 \pm 0.56$ \\
\hline 615 & 1.9 & 0.06 & 71 & 2.50 & 8.76 & 1.6 & 325 & $18.3 \pm 1.37$ \\
\hline 619 & 2.5 & 0.11 & 71 & 3.36 & 13.9 & 4.0 & 228 & $12.9 \pm 0.15$ \\
\hline 620 & 2.8 & 0.11 & 137 & 3.15 & 13.0 & 3.7 & 200 & $12.7 \pm 0.93$ \\
\hline 622 & 1.1 & 0.07 & 31 & 1.52 & 6.27 & 1.2 & 521 & $12.7 \pm 1.15$ \\
\hline 622 & 1.1 & 0.04 & 31 & 1.52 & 6.27 & 0.6 & 523 & $13.3 \pm 1.01$ \\
\hline 770 & 2.9 & 0.15 & 136 & 4.49 & 13.6 & 7.4 & 352 & $26.1 \pm 0.75$ \\
\hline 770 & 2.9 & 0.09 & 136 & 4.49 & 13.6 & 4.5 & 342 & $28.8 \pm 0.99$ \\
\hline 771 & 1.5 & 0.21 & 69 & 6.22 & 12.3 & 14.4 & 488 & $23.1 \pm 1.81$ \\
\hline 771 & 1.5 & 0.14 & 69 & 6.22 & 12.3 & 9.6 & 506 & $22.9 \pm 1.57$ \\
\hline 901 & 1.7 & 0.22 & 68 & 3.80 & 7.86 & 9.2 & 661 & $41.3 \pm 2.72$ \\
\hline 901 & 1.7 & 0.14 & 68 & 3.80 & 7.86 & 5.9 & 737 & $43.1 \pm 2.01$ \\
\hline 907 & 1.8 & 0.23 & 148 & 4.03 & 9.71 & 10.2 & 674 & $40.9 \pm 1.75$ \\
\hline 907 & 1.8 & 0.14 & 148 & 4.03 & 9.71 & 6.2 & 607 & $37.6 \pm 1.92$ \\
\hline 907 & 0.6 & 0.20 & 33 & 1.77 & 4.82 & 3.9 & 1010 & $39.9 \pm 2.43$ \\
\hline 907 & 0.6 & 0.13 & 33 & 1.77 & 4.82 & 2.5 & 1035 & $38.1 \pm 2.17$ \\
\hline
\end{tabular}

$P, T$ and flow measurements leads to $95 \%$ confidence limits of $\pm 8 \%$.

\section{Discussion}

The curvature in Fig. 2 might reflect the influence of low frequency modes in the transition state for a single channel, or the combined effect of multiple channels. Several reaction paths for reaction (1) are thermodynamically feasible

$\mathrm{C}_{6} \mathrm{H}_{5} \mathrm{I}+\mathrm{H} \rightarrow$ 6-iodocyclohexadienyl,

$$
\begin{aligned}
& \Delta_{\mathrm{r}} H_{298}=-205 \mathrm{~kJ} \mathrm{~mol}^{-1} \\
& \mathrm{C}_{6} \mathrm{H}_{5} \mathrm{I}+\mathrm{H} \rightarrow \mathrm{C}_{6} \mathrm{H}_{6}+\mathrm{I}, \quad \Delta_{\mathrm{r}} H_{298}=-194 \mathrm{~kJ} \mathrm{~mol}^{-1} \\
& \mathrm{C}_{6} \mathrm{H}_{5} \mathrm{I}+\mathrm{H} \rightarrow \mathrm{C}_{6} \mathrm{H}_{5}+\mathrm{HI}, \quad \Delta_{\mathrm{r}} H_{298}=-19 \mathrm{~kJ} \mathrm{~mol}^{-1}
\end{aligned}
$$

$\mathrm{C}_{6} \mathrm{H}_{5} \mathrm{I}+\mathrm{H} \rightarrow(1,2$ or 3)-iodocyclohexadienyl,

$$
\Delta_{\mathrm{r}} H_{298}=-110 \mathrm{~kJ} \mathrm{~mol}^{-1}
$$

The reaction enthalpies for (1b) and (1c) are derived from the literature values of $\Delta_{\mathrm{f}} \mathrm{H}_{298}$ for $\mathrm{C}_{6} \mathrm{H}_{5}$ [25], $\mathrm{C}_{6} \mathrm{H}_{5} \mathrm{I}$ [26], $\mathrm{H}$, $\mathrm{HI}$, and I [27] and have uncertainties of at least $6 \mathrm{~kJ} \mathrm{~mol}^{-1}$. $\Delta_{\mathrm{r}} H_{298}^{0}$ for (1a) was estimated from the DFT calculations of Tsao et al., who derived a binding enthalpy for 6-iodocyclohexadienyl, where $\mathrm{H}$ adds ipso to the I atom, of about $11 \mathrm{~kJ} \mathrm{~mol}^{-1}$ relative to $\mathrm{C}_{6} \mathrm{H}_{6}+\mathrm{I}$ [28]. This small value means this $\mathrm{C}_{6} \mathrm{H}_{6} \mathrm{I}$ isomer is not stable enough to be a final product, but it could be an intermediate. Pathway (1d), where $\mathrm{H}$ adds to one of the $\mathrm{C}$ atoms not bonded to $\mathrm{I}$, was assumed to have the same thermochemistry as the addition of $\mathrm{H}$ to benzene [29].

Path (1b) presumably could take place via I-atom elimination from a $\mathrm{C}_{6} \mathrm{H}_{6} \mathrm{I}$ intermediate, or by a concerted mechanism. Similarly, channel (1c) could take place via 


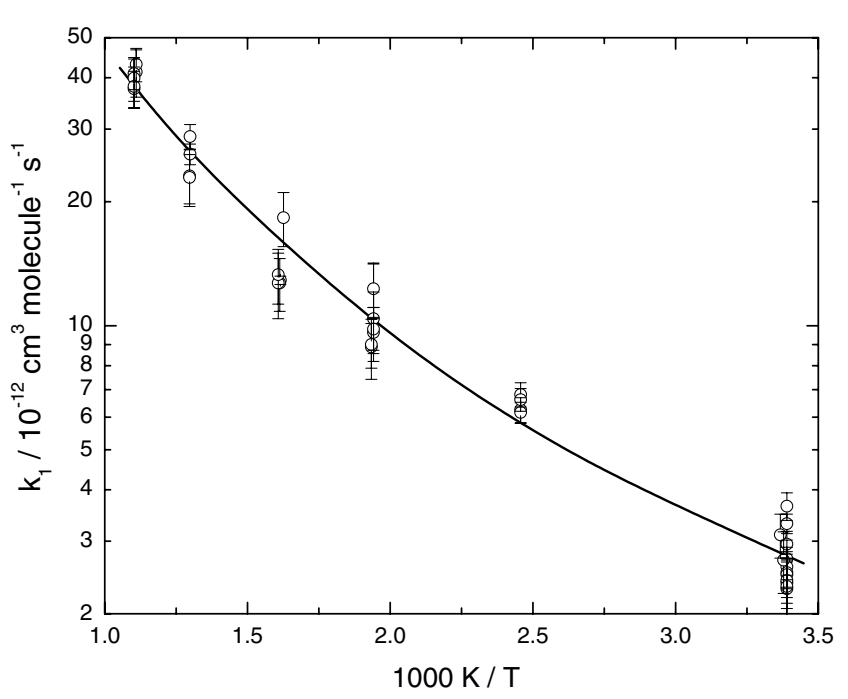

Fig. 2. Arrhenius plot for $\mathrm{H}+\mathrm{C}_{6} \mathrm{H}_{5} \mathrm{I}$. Error bars represent $2 \sigma$. The solid line is an empirical fit to the form $k_{1}=A T^{B} \exp (-C / T)$ (see text).

direct abstraction or elimination of $\mathrm{HI}$ from a $\mathrm{C}_{6} \mathrm{H}_{6} \mathrm{I}$ intermediate. Assuming a similar reaction endothermicity as in the case of $\mathrm{H}+\mathrm{C}_{6} \mathrm{H}_{6}$, abstraction of $\mathrm{H}$ to form $\mathrm{H}_{2}$ plus an iodo-phenyl radical will be negligibly slow [29]. A comparison of the rate constant for $\mathrm{H}+\mathrm{C}_{6} \mathrm{H}_{5} \mathrm{I}$ with that for $\mathrm{H}+\mathrm{C}_{6} \mathrm{H}_{6}$ addition to make cyclohexadienyl [29] is shown in Fig. 3, which indicates that addition to the benzene ring ortho, meta or para to the I atom (pathway (1d)) would be too slow to account for our observations, although a small branching ratio is not excluded. $\mathrm{H}+\mathrm{CH}_{3} \mathrm{I}$ and $\mathrm{H}+\mathrm{C}_{2} \mathrm{H}_{5} \mathrm{I}$ are also shown in Fig. 3, and it may be seen that reaction (1) is slightly slower than the $\mathrm{H}+$ alkyl iodide reactions, which is consistent with the stronger $\mathrm{C}-\mathrm{I}$ bond in the aromatic system: $D H_{298}$ for $\mathrm{C}_{6} \mathrm{H}_{5} \mathrm{I}, \mathrm{CH}_{3} \mathrm{I}$ and $\mathrm{C}_{2} \mathrm{H}_{5} \mathrm{I}$ is $279 \pm$ $6,237.2 \pm 1.3$ and $236.8 \pm 1.7 \mathrm{~kJ} \mathrm{~mol}^{-1}$, respectively.

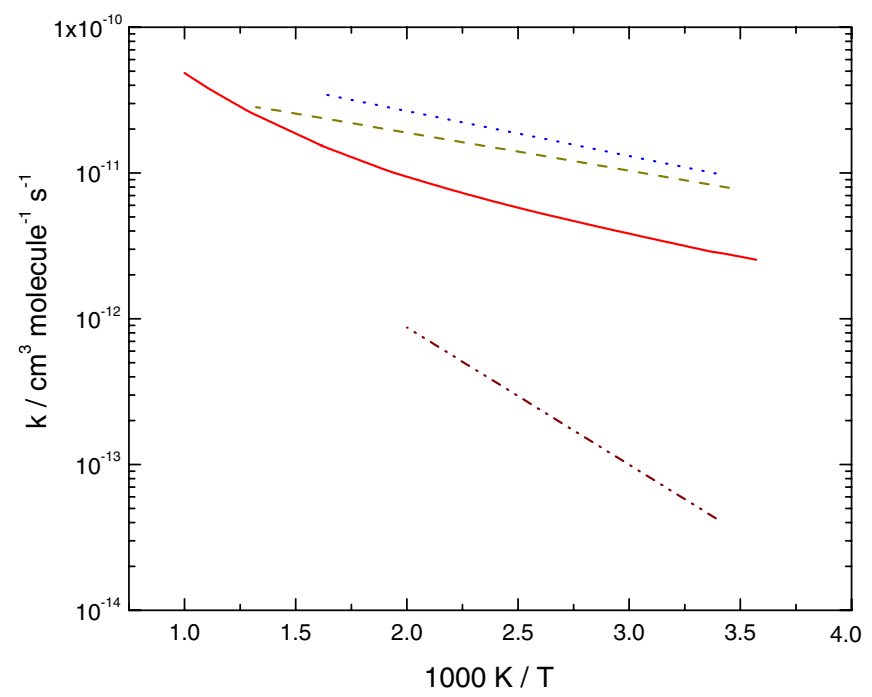

Fig. 3. Comparison of rate constants for $\mathrm{H}+\mathrm{C}_{6} \mathrm{H}_{5} \mathrm{I}$ (solid line) with those for $\mathrm{H}+\mathrm{C}_{2} \mathrm{H}_{5} \mathrm{I}$ (dotted line), $\mathrm{H}+\mathrm{CH}_{3} \mathrm{I}$ (dashed line), and $\mathrm{H}+\mathrm{C}_{6} \mathrm{H}_{6}$ (dash-dot).
$A b$ initio calculations have been carried out to gain further insight into the reaction mechanism. Geometries and frequencies (unscaled) were obtained with the B3LYP density functional [30], the cc-pVTZ basis set for carbon and hydrogen [31], and the cc-pVTZ-PP basis set of Peterson et al. [32] for iodine. This triple zeta basis set includes an effective core potential to account for scalar relativistic effects. Vector relativistic effects (spin-orbit splitting) are important for I atoms, whose energy at $0 \mathrm{~K}$ was corrected downwards by $30.3 \mathrm{~kJ} \mathrm{~mol}^{-1}$ [33]. Refined single-point energies were derived with QCISD theory [34] and the same basis set. Calculations were carried out with the GAUSSIAN 03 program suite [35] and the results are summarized in Table 2. QCISD is variational and largely unaffected by spin-contamination. This property is important because several of the species considered had Hartree-Fock spin expectation values $<S^{2}>$ significantly greater than the ideal value of 0.75 for a doublet radical (see Table 2). Spin-contamination was much less significant in the density functional calculations.

Two reaction paths were characterized, and are shown in Fig. 4. The theoretical $0 \mathrm{~K}$ reaction enthalpies, combined with $H_{298}-H_{0}$ values either from the literature [25,27] or computed here $\left(17.9 \mathrm{~kJ} \mathrm{~mol}^{-1}\right.$ for $\left.\mathrm{C}_{6} \mathrm{H}_{5} \mathrm{I}\right)$, yield $\Delta_{\mathrm{r}} H_{298}=-204$ and $-15 \mathrm{~kJ} \mathrm{~mol}^{-1}$ for channels (1b) and (1c), respectively. These values are in reasonable agreement with the experimental data given above. Channel (1b), addition of $\mathrm{H}$ to the $\mathrm{C}$ atom bound to $\mathrm{I}$, yields the 6-iodocyclohexadienyl radical which dissociates very easily to benzene + atomic iodine. The short lifetime for 6-iodocyclohexadienyl makes it unlikely that it more rapidly eliminates HI to leave phenyl, or that it could be collisionally stabilized. A significant barrier was found at the entrance of this addition path, which would make it to too slow to contribute significantly to the kinetics. This $\mathrm{C}_{6} \mathrm{H}_{5} \mathrm{I}$ species has extremely weak $\mathrm{C}-\mathrm{I}$ bonding, with a computed $D H_{0}$ of about $3 \mathrm{~kJ} \mathrm{~mol}^{-1}$ (based on the assumption that the spin-orbit splitting of atomic $\mathrm{I}$ is not quenched in $\mathrm{C}_{6} \mathrm{H}_{5} \mathrm{I}$ ) which is typical for a van der Waals interaction. Our binding energy is smaller than that computed by Tsao et al. [28]. Presumably our larger basis set is less vulnerable to basis set superposition error, and we would expect QCISD theory to be more reliable than the BH\&HLYP functional employed previously [28].

Relaxed scans at the B3LYP/cc-pVTZ-PP level for channel (1c), direct abstraction of I by H, were performed with a series of fixed $\mathrm{I}-\mathrm{H}$ separations, and at each separation the rest of the structure was optimized to an energy minimum. The results indicate there is no classical energy barrier. This channel then appears to be dominant, and proceeds via a weakly bound exit complex between phenyl and hydrogen iodide. The empirical rate constant expression (5) can be considered in the context of transition state theory, where an expression of the form $D(T) \exp (-E / R T)$ is expected. $E$ is the energy barrier and $D(T)$ is a temperature dependent term reflecting the ratios of the partition functions for the transition state and the reactants, which 
Table 2

$A b$ initio energies and frequencies of reactants, products, and transition states for the $\mathrm{C}_{6} \mathrm{H}_{5} \mathrm{I}+\mathrm{H}$ reaction

\begin{tabular}{|c|c|c|c|}
\hline Species & Frequencies $^{\mathrm{a}}\left(\mathrm{cm}^{-1}\right)$ & $<S^{2}>$ & Energy $^{\mathrm{b}}(\mathrm{au})$ \\
\hline $\mathrm{H}$ & & 0.750 & -0.49981 \\
\hline I & & $0.760(0.753)^{\mathrm{c}}$ & -296.87521 \\
\hline HI & 2317 & 0.000 & -297.49934 \\
\hline $\mathrm{C}_{6} \mathrm{H}_{6}$ & $\begin{array}{l}41441562462469172786686998898910151022103110621062117712001200 \\
133513901518151916371637315831683168318331843194\end{array}$ & 0.000 & -231.75526 \\
\hline $\mathrm{C}_{6} \mathrm{H}_{5} \mathrm{IH}$ & $\begin{array}{l}11242812214340342960162467472681490097099410011019105410761179 \\
1179130613281469147715731631228031603166317931823191\end{array}$ & $1.337(0.757)^{\mathrm{c}}$ & -528.56576 \\
\hline $\mathrm{C}_{6} \mathrm{H}_{6} \mathrm{I}$ & $\begin{array}{l}184793408411618620697718863880993996100810251030105410621180 \\
119512021340139115111517161216293168317931803192 \quad 31943202\end{array}$ & $1.201(0.753)^{\mathrm{c}}$ & -528.63185 \\
\hline $\mathrm{C}_{6} \mathrm{H}_{6} \mathrm{I}$ TS & $\begin{array}{l}-9501472062573924424515016236586987578409239851005101210241056 \\
11001183120512971349147014931592160231703178319332033205\end{array}$ & $1.370(0.770)^{\mathrm{c}}$ & -528.53969 \\
\hline
\end{tabular}

${ }^{\text {a }}$ B3LYP/cc-pVTZ-PP.

${ }^{\mathrm{b}}$ QCISD/cc-pVTZ-PP including ZPE; $1 \mathrm{au} \approx 2625.5 \mathrm{~kJ} \mathrm{~mol}^{-1}$.

${ }^{c}$ B3LYP value.

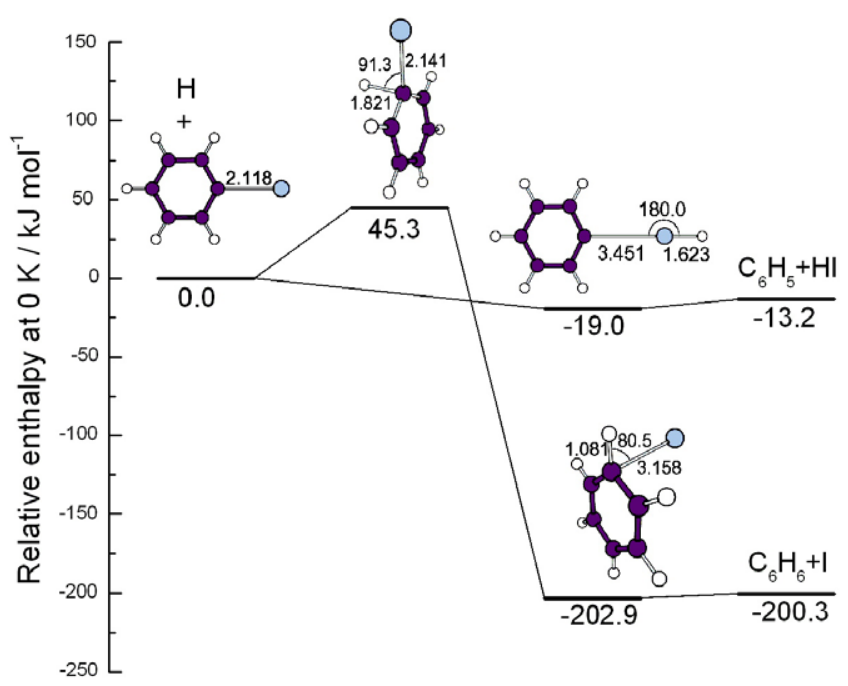

Fig. 4. Potential energy diagram for $\mathrm{H}+\mathrm{C}_{6} \mathrm{H}_{5} \mathrm{I}$ reaction paths, based on QCISD/cc-pVTZ-PP//B3LYP/cc-pVTZ-PP calculations.

can be approximately expressed in the form $A T^{n}$ [36]. Cohen has noted that $\mathrm{n}$ could be as high as 2.2 , or even larger if the transition state is very loose [36]. Such values of $n$ with $E \approx 0$ are approximately consistent with the parameters in Eq. (5). A more detailed rationalization would require a variational transition state theory analysis.

\section{Conclusions}

The laser flash-photolysis resonance fluorescence technique has been used to measure the rate constant for the reaction of $\mathrm{H}$ atoms with iodobenzene. The temperature dependence of the rate constant shows non-Arrhenius behavior, and $a b$ initio analysis of the possible reaction pathways suggests the dominant products are $\mathrm{HI}+\mathrm{C}_{6} \mathrm{H}_{5}$, rather than the more thermodynamically stable products $\mathrm{C}_{6} \mathrm{H}_{6}+\mathrm{I}$.

\section{Acknowledgments}

This work was supported by the Robert A. Welch Foundation (Grant B-1174) and the UNT Faculty Research Fund. We are also grateful for support from the NSF REU program (KF, Grant CHE 0243795) and the Texas Academy of Mathematics and Science (CM). The excimer laser and computer facilities were purchased with NSF Grants CTS-0113605 and CHE-0342824, respectively.

\section{References}

[1] I.O. Leipunskii, I.I. Morozov, V.L. Tal'roze, Dokl. Phys. Chem. 198 (1971) 547, Russ. Orig, p. 1367.

[2] R.E. Rebbert, S.G. Lias, P. Ausloos, Int. J. Chem. Kinet. 5 (1973) 893.

[3] M.R. Levy, J.P. Simons, J. Chem. Soc., Faraday Trans. 2 (71) (1975) 561.

[4] A. Sillesen, E. Ratajczak, P. Pagsberg, Chem. Phys. Lett. 201 (1993) 171.

[5] P. Marshall, A. Misra, R.J. Berry, Chem. Phys. Lett. 265 (1997) 48.

[6] J. Yuan, L. Wells, P. Marshall, J. Phys. Chem. A 101 (1997) 3542.

[7] M.K. Gilles et al., J. Phys. Chem. 100 (1996) 14005.

[8] W. Tsang, A.W. Miziolek (Eds.), Halon Replacements: Technology and Science, ACS Symposium Series, vol. 611, American Chemical Society, Washington, DC, 1995.

[9] Y.V. Ayhens, J.M. Nicovich, M.L. McKee, P.H. Wine, J. Phys. Chem. A 101 (1997) 9382.

[10] J.P. Reid, C.X.W. Qian, S.R. Leone, Phys. Chem. Chem. Phys. 2 (2000) 853

[11] D.M. Tomkinson, H.O. Pritchard, J. Phys. Chem. 70 (1966) 1579.

[12] A.S. Rodgers, D.M. Golden, S.W. Benson, J. Am. Chem. Soc. 89 (1967) 4578.

[13] M.P.S. Andersen, D.A. Ponomarev, O.J. Nielsen, M.D. Hurley, T.J. Wallington, Chem. Phys. Lett. 350 (2001) 423.

[14] T.J. Wallington, D.M. Neuman, M.J. Kurylo, Int. J. Chem. Kinet. 19 (1987) 725.

[15] Y. Shi, P. Marshall, J. Phys. Chem. 95 (1991) 1654. 
[16] L. Ding, P. Marshall, J. Phys. Chem. 96 (1992) 2197.

[17] A. Goumri, W.-J. Yuan, L. Ding, P. Marshall, Chem. Phys. 177 (1993) 233.

[18] J. Peng, X. Hu, P. Marshall, J. Phys. Chem. A 103 (1999) 5307.

[19] L. Ding, P. Marshall, J. Chem. Soc., Faraday Trans. 89 (1993) 419.

[20] P. Marshall, A. Fontijn, J. Chem. Phys. 85 (1986) 2637.

[21] P. Marshall, Comput. Chem. 11 (1987) 219.

[22] P. Marshall, Comput. Chem. 13 (1989) 103.

[23] F.Z. Chen, D.L. Judge, C.Y.R. Wu, J. Caldwell, Planet. Space Sci. 47 (1999) 261.

[24] S.S. Kumaran, M.C. Su, J.V. Michael, Chem. Phys. Lett. 269 (1997) 99.

[25] I.M. Alecu, Y. Gao, P.C. Hsieh, J.P. Sand, A. Ors, A. McLeod, P. Marshall, J. Phys. Chem. A 111 (2007) 3970.

[26] J.B. Pedley, R.D. Naylor, S.P. Kirby, Thermochemical Data of Organic Compounds, second ed., Chapman and Hall, London, 1986.

[27] M.W. Chase Jr. (Ed.), NIST-JANAF Thermochemical Tables, fourth ed., American Chemical Society, American Institute of Physics, Woodbury, NY, 1998.
[28] M.-L. Tsao, C.M. Hadad, M.S. Platz, J. Am. Chem. Soc. 125 (2003) 8390.

[29] J.M. Nicovich, A.R. Ravishankara, J. Phys. Chem. 88 (1984) 2534.

[30] A.D. Becke, J. Chem. Phys. 98 (1993) 5648.

[31] T.H. Dunning Jr., J. Chem. Phys. 90 (1989) 1007.

[32] K.A. Peterson, D. Figgen, E. Goll, H. Stoll, M. Dolg, J. Chem. Phys. 119 (2003) 11113.

[33] R.J. Berry, M. Schwartz, P. Marshall, in: K.K. Irikura, D.J. Frurip (Eds.), Computational Thermochemistry: Prediction and Estimation of Molecular Thermodynamics, ACS Symposium Series, vol. 677, ACS, Washington, DC, 1998, Chapter 18

[34] J.A. Pople, M. Head-Gordon, K. Raghavachari, J. Chem. Phys. 87 (1987) 5968.

[35] M.J. Frisch et al., Gaussian 03, Revision D.02, Gaussian, Wallingford, CT, 2004.

[36] N. Cohen, Int. J. Chem. Kinet. 21 (1989) 909. 